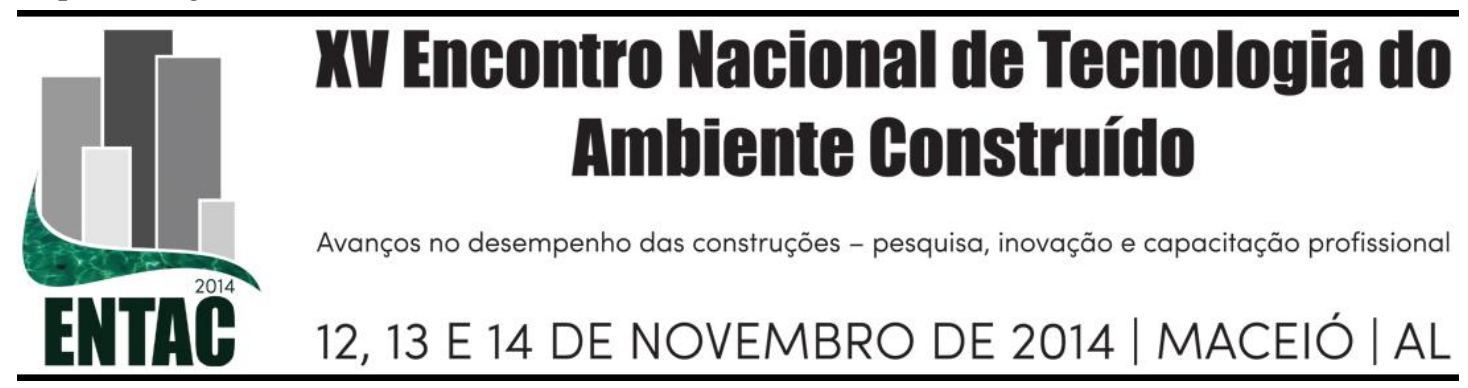

\title{
AVALIAÇÃO PÓS-OCUPAÇÃO, COM ÊNFASE NA FUNCIONALIDADE DOS EDIFÍCIOS DE SALAS DE AULAS TEÓRICAS - ATS, NO CAMPUS DE SÃO CARLOS DA UFSCAR
}

\author{
SILVA, Ricardo Siloto da (1); CÁCERES, Jezreel Bomfim Omido (2); \\ PALOMARES, Rodrigo Fonseca (3)
}

(1) Universidade Federal de São Carlos-UFSCar, e-mail: silotosilva@gmail.com, (2) UFSCar, e-mail: je.omido@gmail.com, (3) UFSCar, e-mail: rtpalomares@uol.com.br

\begin{abstract}
RESUMO
O objetivo deste trabalho foi aplicar a APO - Avaliação Pós Ocupação, na variável funcionalidade, em três (3) edifícios de aulas teóricas, ATs - tipos, da Universidade Federal de São Carlos, buscando identificar os aspectos positivos e os negativos das diferentes soluções adotadas e assim constituir parâmetros para os novos projetos de ATs. O método utilizado contou, além da revisão da literatura técnica-científica, compilação e sistematização das técnicas aplicáveis ao projeto; estruturação e elaboração dos instrumentos de pesquisa; aplicação de questionários múltipla escolha para os alunos usuários de cada edifício; aplicação de entrevista estruturada com os professores e bedéis de cada edifício; visitas técnicas documentadas e a tabulação dos resultados. A pesquisa pode ser classificada como estudo de caso, com caráter exploratório. Em síntese, os resultados apontaram para uma evolução positiva entre os projetos, realizados em épocas subsequentes, em especial no que se refere ao conforto higrotérmico, iluminação natural e à concepção estrutural. Em todos a avaliação quanto à localização foi satisfatória. Por outro lado foram apontados aspectos a serem aprimorados em particular quanto à segurança, disposição de sanitários, acessibilidade, mobiliário e disposição dos elementos do sistema elétrico e de iluminação (nas salas de aula). Os resultados da pesquisa serão disponibilizados para os setores responsáveis pelos projetos e fiscalização de obras, visando a sua utilização tanto em projetos futuros como em projetos de reformas e melhorias desses edifícios.
\end{abstract}

Palavras-chave: APO (Avaliação Pós-Ocupação), funcionalidade, UFSCar, projeto de edifício.

\begin{abstract}
The aim of this work was to apply the Post Occupancy Evaluation (POE) in variable functionality to three (3) buildings for the purpose of theoretical classes at the Federal University of São Carlos, Brazil (UFSCar). The objective was to identify positive and negative aspects of different adopted solutions and, therefore, set parameters for new projects in the theoretical classes. The method consisted of: a technoscientific literature review compiling and systematizing applicable techniques for the project; structuring and developing research instruments; conducting multiple choice questionnaires with students who use each building; carrying out a structured interview with lecturers and inspectors from each building; technical visits registered in the buildings and a table of the results was made. The research can be classified as a case study having an exploratory nature. To sum up, the results showed positive progress in the projects, which were carried out in subsequent periods, especially concerning hygrothermal comfort, natural light and structural conception. In all of them, the evaluation and location were satisfactory. On the other hand, some aspects need to be improved such as security, layout of the bathrooms, accessibility, electrical system layout and lighting in the classrooms. The results of the research will be available for the sectors responsible for projects and construction, aiming to help future projects concerning renovation and improving these buildings.
\end{abstract}


Keywords: Post Occupancy Evaluation (POE), functionality, UFSCar, building project.

\section{1- INTRODUÇÃ̃O}

Pela sua própria natureza, ao longo de sua história, a Universidade Federal de São Carlos tem feito sucessivas edificações com a finalidade de ministrar as aulas teóricas. Tendo programas bastante semelhantes, as estratégias projetuais e construtivas dos edifícios mais antigos têm se constituído em referências (positivas ou negativas) para os mais novos. A condição de replicabilidade desse tipo de edificação favorece a possibilidade da utilização da Avaliação Pós-ocupação - APO, o que poderá trazer a percepção do usuário sobre o desempenho da mesma. Assim, o objetivo da pesquisa aqui apresentada foi o da aplicação desse instrumento, na variável funcionalidade, em três (3) edifícios-tipo de aulas teóricas, ATs, construídos no campus sede na Universidade Federal de São Carlos.

Entende-se que este estudo poderá contribuir com a qualidade do ambiente construído na universidade ao promover uma retroalimentação no processo projetual, trazendo de forma sistematizada a percepção dos usuários deste tipo de edificação no campus de São Carlos. Para tal, o resultado da pesquisa está sendo disponibilizado para o Escritório de Desenvolvimento Físico (EDF), órgão responsável pela consecução e pela avaliação dos projetos edilícios (arquitetura e engenharia) na universidade.

\section{2- AVALIAÇÃO PÓS-OCUPAÇÃO}

A literatura técnico-científica, que tem como objeto o estudo do Projeto de Edificações, considera que o processo de construção é composto por três macro-fases: a da concepção - que envolve os levantamentos, a elaboração do Programa de Necessidades e o projeto propriamente dito; a da produção - que equivale à execução da obra - e a de uso, manutenção e operação, que se refere ao envolvimento do usuário final no produto pronto (edificação). Esta última, que é de longa duração, traz uma importante possibilidade de contribuir para o aprimoramento de novos projetos semelhantes (em qualquer uma das suas macro-fases) por meio da utilização da técnica de Avaliação Pósocupação (APO).

A estruturação da APO, como ela é praticada nos dias atuais, teve como origens principais a psicologia ambiental (décadas de 40 e 50), que estuda as relações entre ambiente e comportamento; o desempenho construtivo dos edifícios, em especial o preconizado pelo US National Insitute of Standards and Technology e Committee E06 on Perfomance of Buildings of ASTM; e a consolidação das propostas da Architectural Programming. Apesar desta técnica estar disponível desde o final dos anos 60, e ser bem desenvolvida nos meios acadêmicos, ela ainda não é utilizada, de forma sistemática e constante, no processo projeto - construção - utilização de edifícios, mesmo em situações de repetição de Programa de Necessidades ou de replicação de projetos.

Entendemos que a APO pode complementar o estabelecido pela NBR 15.575, da ABNT - Associação Brasileira de Normas Técnicas, contribuindo para ampliar a avaliação de desempenho. Esta Norma, que começou a vigorar em junho de 2013 e se restringe a edifícios habitacionais, reforça, mais uma vez, a importância de se olhar a edificação por meio do desempenho da mesma, seja como unidade ou pelo conjunto dos seus sistemas, componentes, elementos ou materiais utilizados.

A técnica da APO, Avaliação Pós-ocupação, consiste em um conjunto de procedimentos, análises e avaliações que envolve diferentes variáveis, como, por exemplo: 
- Em relação aos sistemas construtivos: técnica construtiva; instalações elétricas e consumo energético; qualidade construtiva, qualidade dos acabamentos e segurança contra incêndio etc.

- Em relação ao conforto ambiental: conforto lumínico; conforto acústico, conforto higrotérmico, entre outros;

- Em relação à economia: custos de projeto, produção e manutenção, vistos ao longo do tempo e analisados comparativamente a outras alternativas construtivas e a outras edificações semelhantes;

- Em relação à estética: cores / pigmentação; texturas; volumetria; percepção ambiental; efeitos lumínicos, etc;

- Em relação à habitabilidade e funcionabilidade: adequação à função; conforto ergonômico; relação entre os ambientes da edificação; relação da edificação com seu entorno; flexibilidade espacial; adequação mobiliário / equipamentos ao ambiente; acessibilidade; circulação interna aos ambientes e à edificação; relação entre dimensionamentos praticados e dimensionamentos mínimos; respeito à escala humana, etc.

A avaliação do desempenho da edificação, vista pela percepção do usuário, pode contribuir, através da retroalimentação, de forma bastante significativa, para a melhoria da qualidade de projetos e de construções. Esse procedimento poderá proporcionar, portanto, situações de maior grau de satisfação em relação ao produto bem como racionalização em processos construtivos, diminuição de impactos ambientais decorrentes desses processos, maior eficiência energética, maior segurança no uso, melhores estanqueidade e estabilidade, maiores condições de prevenção quanto à manutenabilidade, entre outros fatores.

\section{3- OBJETO DE ANÁLISE}

A UFSCar, universidade criada em 1968, a partir de meados dos anos 70, decidiu pela concentração das aulas teóricas em edifícios específicos projetados para esse fím. Esses edifícios, denominados AT (Aulas Teóricas), atendiam, assim, a diferentes cursos e passaram a serem localizados de forma dispersa pelo campus, procurando uma relativa equidistância com os departamentos acadêmicos e com as atividades coletivas mais concentradoras, como a Biblioteca e o Restaurante Universitário. Desse período inicial até meados da primeira década do presente século foram edificados 5 ATs no campus de São Carlos. A partir da adesão da universidade à Reestruturação e Expansão das Instituições Federais de Ensino Superior (REUNI), programa do Ministério da Educação, houve uma significativa ampliação de vagas e cursos e a decorrente implantação de mais 5 ATs, sendo 4 em novas edificações e um adaptação de prédio já existente. Neste período houve a mudança de uso em um dos ATs, em virtude da má condição de conforto acústico do mesmo. Este, o antigo AT3, foi desativado como locus de aulas teóricas e atende, hoje, a outras finalidades: sala para estudos em grupo, área de apoio aos alunos do cursinho e secretaria dos cursos de graduação feitos à distância. Além destes, em outros campi da instituição (Sorocaba e Araras) têm sido construídas edificações semelhantes para a mesma função.

.As unidades dos ATs têm Programas de Necessidades semelhantes e demonstram uma progressiva tentativa de melhorias ambientais e construtivas ao longo da implantação das mesmas. De forma geral, pode-se identificar que o AT1 apresenta uma concepção; os AT2, AT4 e AT5 outra proposta construtiva e arquitetônica; o AT6, AT7, AT8 e 
AT9 representam um terceiro momento na abordagem projetual. Entre estes últimos vale destacar uma similaridade maior entre o AT7 e AT9.

Para o presente estudo, foram selecionadas as seguintes edificações: AT1, inaugurado em 1977 e localizado na área sul do campus com uma área de 1.599,00 metros quadrados; AT4, inaugurado em 1994 e localizado na área norte do campus, com uma área de 1.673,70 metros quadrados e AT9, inaugurado em 2011 e localizado na Área de Expansão Norte do campus, com uma área de 2.472,30 metros quadrados (Quadro 1). Os critérios utilizados para a seleção foram: (1) cada um destes representa uma das tipologias existentes entre os ATs; (2) cada um destes são marcos referenciais dos diferentes momentos na história da evolução das estratégias projetuais adotadas pela instituição para esse tipo de Programa de Necessidades

\section{Quadro 1 - Edifícios de Aula Teórica Analisados}

\begin{tabular}{|c|c|c|c|}
\hline Edifício & Localização & $\begin{array}{c}\text { Ano de } \\
\text { Inauguração }\end{array}$ & Área $\left(\mathbf{m}^{\mathbf{2}}\right)$ \\
\hline AT1 & Área Sul & 1977 & $1.599,00$ \\
\hline AT4 & Área Norte & 1994 & $1.673,70$ \\
\hline AT9 & Área de Expansão Norte & 2011 & $2.472,30$ \\
\hline
\end{tabular}

As Fotografias 1, 2 e 3 mostram os edifícios selecionados para essa pesquisa.

É importante ressaltar que CUNHA, R.J. (2010) realizou pesquisa de APO para o AT7. A metodologia da mesma foi objeto de estudo do presente trabalho.

Fotografia 1 - AT1

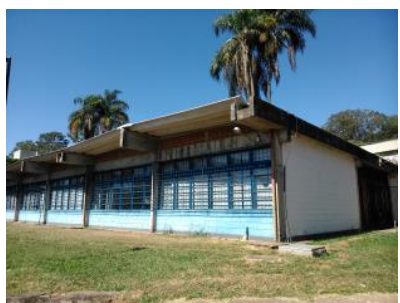

Fotografia 2 - AT4

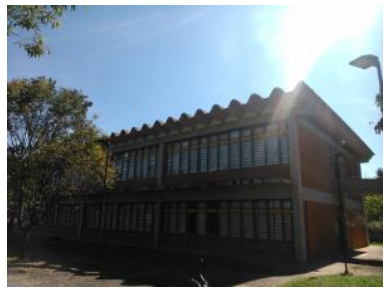

Fotografia 3- AT9

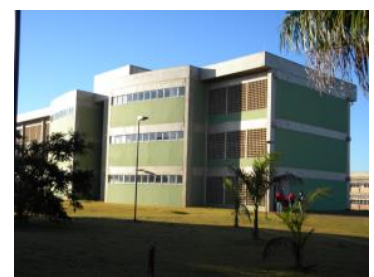

Por essa condição de replicabilidade, entende-se que esse tipo de edificação é muito propícia a ser objeto da técnica de Avaliação Pós-ocupação, realimentando e aprimorando a qualidade projetual e construtiva da mesma.

\section{4- METODOLOGIA}

\subsection{Objetivo}

Essa pesquisa tem como objetivo principal a Avaliação Pós-ocupação da funcionalidade de edifícios destinados a Aulas Teóricas (ATs) no campus de São Carlos, da UFSCar e como objetivo secundário, uma comparação entre os mesmos, considerando cada variável analisada. 


\subsection{Variáveis de análise}

O estudo realizado sobre 3 ATs, uma edificação de cada tipo, considerou as seguintes variáveis de análise:

- Adequação do ambiente ao uso;

- Conforto ambiental - lumínico, acústico, higrotérmico;

- Estética

- Conforto ergonômico do mobiliário;

- Segurança e acessibilidade das circulações verticais e horizontais.

- Locação - facilidade de acesso a outros ATs e a edificações de interesse coletivo no campus.

\subsection{Instrumentos e Plano de Trabalho}

A metodologia utilizou vários instrumentos complementares, pensados de acordo com a caracterização dos principais atores sociais partícipes da pesquisa. Assim, entre os alunos usuários foi aplicado questionário múltipla escolha; entre os docentes usuários foram utilizadas entrevistas com respostas abertas e com os funcionários do edifício, que atuam na limpeza e no apoio, foram realizadas entrevistas orientadas. O protocolo de pesquisa proposto previu, ainda, como atividade inicial, visita técnica orientada em cada unidade edilícia, utilizando-se a observação dos pesquisadores, e iniciando-se a documentação fotográfica da unidade e do seu uso. Essa atividade teve como referência o citado no livro "Lugar: procedimentos para a Avaliação Pós-Ocupação" de RHEINGANTZ et al (2009).

Mesmo sem levantar parâmetros quantitativos, optou-se pela aplicação de técnicas diversificadas, questionários e entrevistas, dirigidas a diferentes tipos de usuários alunos, docentes e bedéis. Na constatação de Orstein e Roméro, diferentes fontes e técnicas podem trazer maior precisão à avaliação:

“(...) a diversidade de métodos e técnicas adotados (questionários, entrevistas, observações, registros fotográficos, vistorias técnicas, outros), sendo alguns com resultados predominantemente quantitativos $e$ outros com resultados predominantemente qualitativos, $e$ a comparação entre eles aumentam a confiabilidade dos diagnósticos finais e de seus cruzamentos;" (ORSTEIN; ROMÉRO, 2003, p.51).

As etapas de pesquisa foram:

- Revisão da literatura técnico-científica sobre Avaliação Pós-ocupação (APO) aplicável a Edificações, em especial as de uso educacional, priorizando as avaliações quanto à funcionalidade. Esse momento tem como objetivo principal capacitar o orientando para a utilização da técnica APO. (HEFCE, 2006; PREISER, 2005; ZANCUL, 2007)

- Compilação e sistematização das técnicas aplicáveis ao objeto.

- Sistematização das técnicas identificadas como base para a estruturação dos instrumentos de avaliação.

- Planejamento e realização da pesquisa:

- Estruturação dos instrumentos.

- Percepção dos pesquisadores sobre cada unidade edilícia por meio de visita técnica orientada, com período de observação, verificando 
principalmente aspectos construtivos, arquitetônicos e características de uso.

- Levantamento junto ao Escritório de Desenvolvimento Físico da UFSCar dos dados projetuais de cada unidade analisada.

- Aplicação de questionário múltipla escolha, junto aos alunos usuários.

- Aplicação de questionário com respostas abertas junto aos docentes usuários.

- Realização de entrevista orientada junto aos funcionários do edifício (bedéis).

- Análise dos resultados:

- Sistematização e tabulação dos dados coletados.

- Análise comparativa entre as unidades edilícias pesquisadas, feita por variável de análise.

As questões iniciais do questionário buscaram caracterizar os respondentes (alunos) quanto ao gênero, curso e tempo de vínculo com a instituição. As demais questões foram sobre a condição da edificação em si e sua situação com o entorno. A primeira parte buscou avaliar a percepção quanto ao conforto térmico em geral, ao mobiliário das salas de aula, os corredores, as escadas, os elevadores, a segurança e a estética. Ao final, procurou-se avaliar a questão locacional, principalmente quanto ao acesso a outros ATs, a papelarias e reprografia, às áreas de estudos e descanso e aos estacionamentos. Houve a preocupação de se estabelecer uma relação direta entre as perguntas do questionário, dirigido para os alunos, e as entrevistas dirigidas, tanto as feitas com os docentes como as feitas com os bedéis.

Tanto os questionários (alunos) e como as entrevistas (professores e funcionários) abordaram 14 itens relativos à edificação em si; 7 itens relativos a mobiliário ou equipamentos e 5 itens relativos à situação locacional da edificação.

As entrevistas com os professores e os funcionários também tiveram questões mais abrangentes e abertas.

Os três conjuntos de respostas (alunos, professores e funcionários) foram cotejados entre si e tabulados para uma melhor visualização dos resultados.

\section{5- RESULTADOS E DISCUSSÃO}

Como os ATs analisados refletem épocas diferentes (AT 9 é o mais recente e o AT1 o mais antigo), tanto no que se refere às estratégias projetuais como na própria dinâmica de ocupação do campus, foi possível constatar a evolução existente em cada variável. A seguir são destacados alguns desses resultados.

Em relação à estética, tanto externa como internamente ao edifício, o índice de satisfação dos usuários melhorou significativamente, conforme pode-se constatar nos Gráficos 1 e 2 (onde azul significa péssima; vermelho significa razoável e verde referese a boa / ótima), mostrados a seguir: 


\section{Gráfico 1}

Estética interna ao edifício

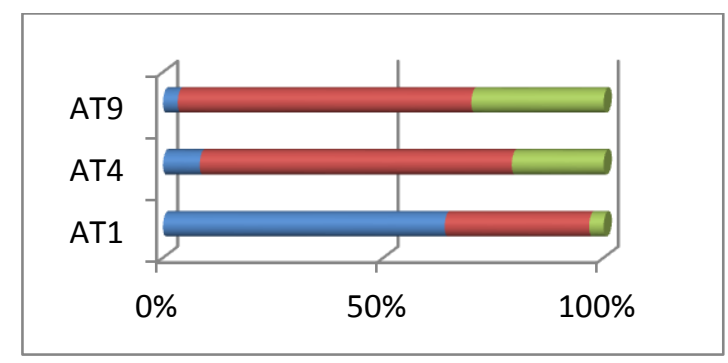

Gráfico 2

Estética externa ao edifício

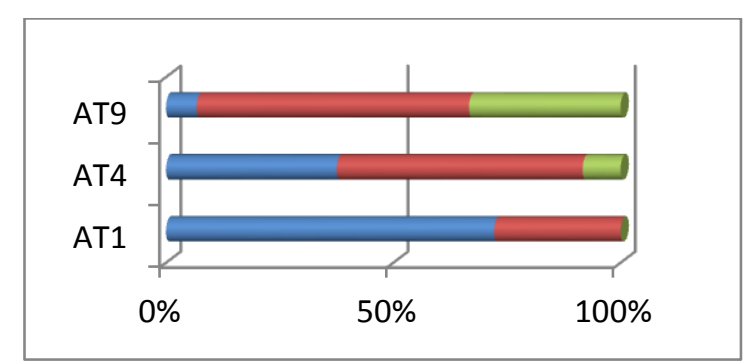

Segundo relato da equipe responsável pelas edificações da universidade, o conforto térmico passivo (sem utilização de equipamentos eletromecânicos) tem sido objeto de especial atenção nas abordagens de projeto de salas de aula, com o cuidado em relação às faces das aberturas, à utilização de ventilação cruzada e de vedação externa com parede dupla de alvenaria, entre outras estratégias adotadas. Mesmo assim, na percepção dos usuários, nesse quesito porém persistiu um alto grau de insatisfação apesar de ter havido uma significa melhora. $\mathrm{O}$ mesmo se reflete quanto à ventilação natural, conforme sintetizado nos Gráficos 3 - Conforto térmico e 4 - Ventilação natural (onde azul significa péssima; vermelho significa razoável e verde refere-se a boa / ótima).

\section{Gráfico 3 - Conforto térmico}

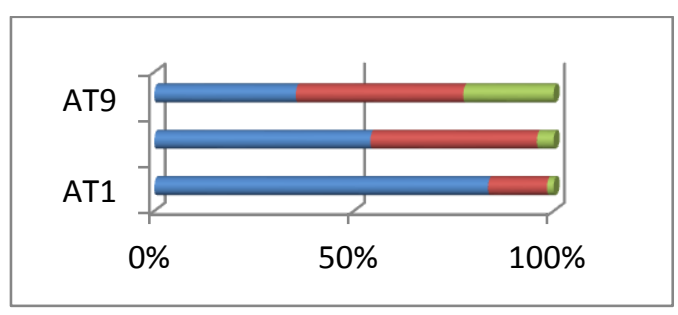

\section{Gráfico 4 - Ventilação natural}

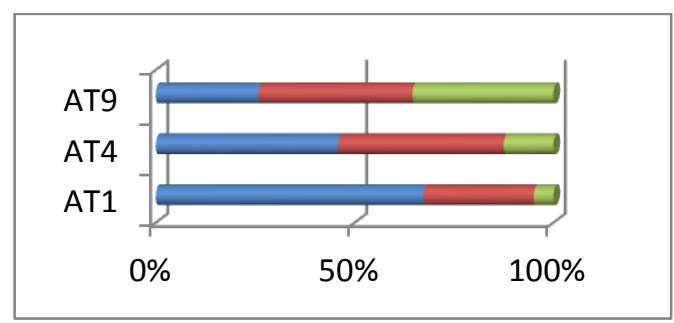

A melhoria do conforto térmico passivo ocorrida entre o existente no AT1 para com o existente no AT9 reduziu a insatisfação com a demanda de ventilação artificial, conforme explicitado no Gráfico 5. Em relação ao conforto lumínico, na percepção dos usuários, houve uma melhoria, tanto na iluminação natural como na artificial (Gráfíco 6) (onde azul significa péssima; vermelho significa razoável e verde refere-se a boa / ótima).

\section{Gráfico 5 - Ventilação artificial}

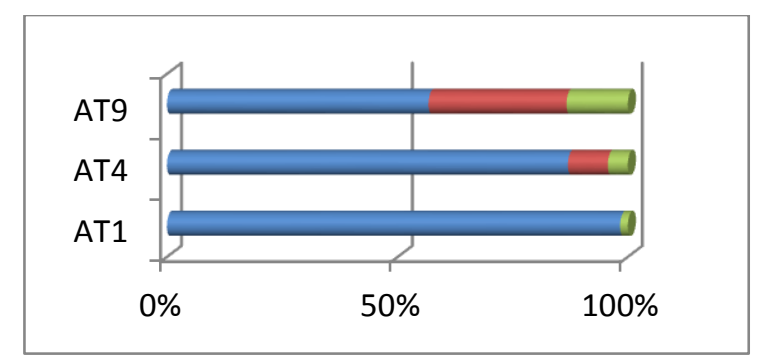

\section{Gráfico 6 - Iluminação artificial}

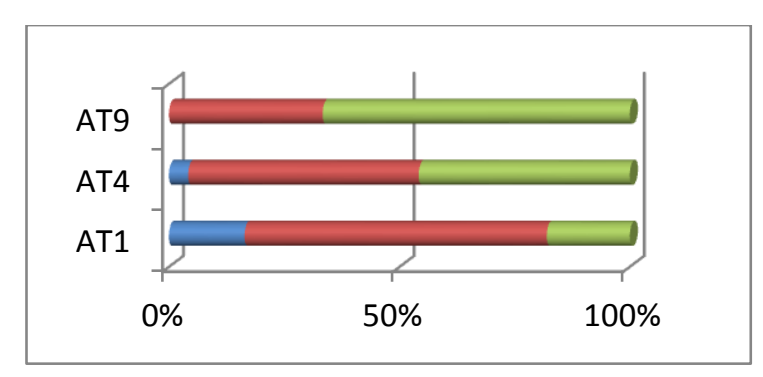

Outro aspecto de evolução positiva foi o da localização e quantidade de banheiros e de bebedouros, que receberam uma avaliação ótima / boa em quase $80 \%$ das respostas no edifício mais recente (AT9). (azul significa péssima; vermelho significa razoável e verde refere-se a boa / ótima).

Processo no 2014/16362-1, Fundação de Amparo à Pesquisa do Estado de São Paulo (FAPESP), pelo apoio na divulgação da pesquisa 
Gráfico 7 - Banheiros

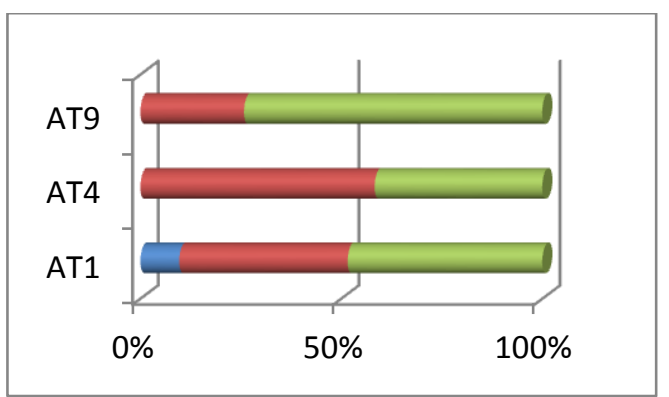

Gráfico 8 - Bebedouros

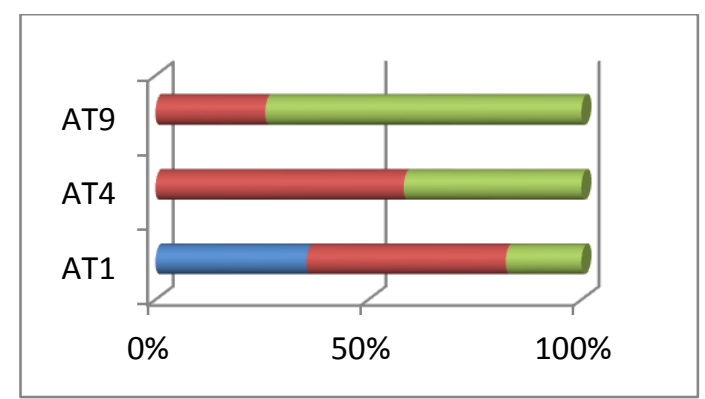

Por fim, importante notar, também, o surgimento de novas demandas, inexistentes quando dos primeiros projetos. Dois exemplos simbólicos: (1) necessidade de ambiente para estudos fora do horário de aulas, surgida como decorrência da política adotada de "fechamento" das salas de aulas teóricas devido questões de segurança surgidas após a instalação de projetos fixos nas mesmas; (2) disponibilidade de rede de internet sem fio aberta em todos os ambientes dos edifícios de ATs. Apesar de serem consideradas justas, essas demandas não estão completamente atendidas, resultando em altos índices de insatisfação no levantamento feio, conforme apontam os Gráficos 9 e 10 (onde azul significa péssima; vermelho significa razoável e verde refere-se a boa / ótima e roxo significa inexistente).

Gráfico 9 - Acesso à internet sem fio

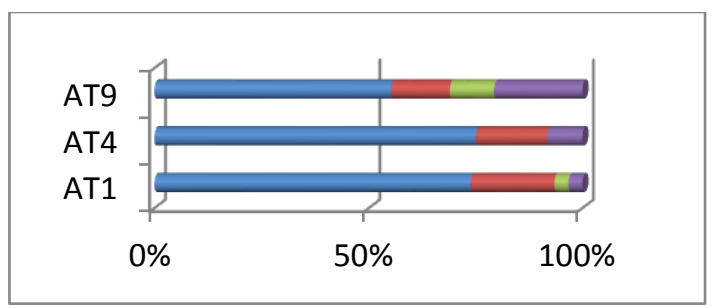

Gráfico 10 - Área de estudo

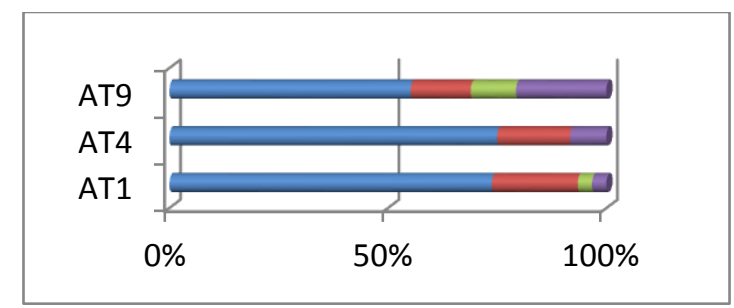

Outros aspectos analisados não apresentaram variações significativas.

\section{6- CONCLUSÃO}

Em síntese, os resultados apontaram para uma evolução positiva entre os projetos, realizados em épocas subsequentes, em especial no que se refere ao conforto higrotérmico, iluminação natural e à localização de apoios como banheiros e bebedouros. No geral, a avaliação quanto à localização foi satisfatória. Por outro lado foram apontados aspectos a serem aprimorados ou implementados, como é o caso de criação de ambientes para estudo (fora do horário das aulas) e a disponibilização de acesso a rede de internet sem fio nos ATs.

Os resultados da pesquisa serão disponibilizados para o Escritório de Desenvolvimento Físico, setor responsável pelos projetos, e para a Prefeitura Universitária, responsável tanto pela fiscalização de obras como pela manutenção predial, visando a sua utilização tanto em projetos futuros como em projetos de reformas e melhorias desses edifícios.

\section{AGRADECIMENTOS}

Ao CNPq pelo apoio à pesquisa. 


\section{REFERÊNCIAS}

CUNHA, R. J.. Avaliação Pós-Ocupação do AT7: Satisfação dos usuários e diretrizes para a melhoria da qualidade dos futuros projetos. 2011. $113 \mathrm{f}$. Trabalho de Conclusão de Curso (Especialização em Gestão Pública) - Departamento de Engenharia de Produção, Universidade Federal de São Carlos, São Carlos; 2010.

HEFCE - Higher Education Funding Council for England. Guide to Post Occupany Evaluation. London: University of Westminster, 2006.

ORNSTEIN, S.W.; ROMÉRO, M.A. Avaliação Pós-Ocupação: Métodos e Técnicas Aplicados à Habitação Social. Porto Alegre: Habitare / FINEP /ANTAC, 2003.

PREISER, W. F. E.; VISCHER J.. Assessing building performance. Oxford: Elsevier, 2005.

RHEINGANTZ, P. A. et al. (eds.) Observando a Qualidade do Lugar: procedimentos para a avaliação pós-ocupação. Rio de Janeiro: Proarq/FAU-UFRJ, 2009.

ZANCUL, J. S.. Habitação estudantil: avaliação pós-ocupação em São Carlos - SP. Dissertação (Mestrado). Escola de Engenharia de São Carlos, Universidade de São Paulo, 2007. 